Research Paper

\title{
High Expression of P38 $\alpha$ and Preoperative Carbohydrate Antigen 19-9 Indicate Poor Prognosis in Patients with Pancreatic Ductal Adenocarcinoma
}

\author{
Jionghuang Chen", Ting Zhao*, Shengnan Jia, Senhao Zhou, Lianging Zhou, Shaowen Wang, Guoping \\ Ding, Guixing Jiang, Liping Cao ${ }^{\bowtie}$ \\ Department of General Surgery, Sir Run Run Shaw Hospital, the affiliated hospital of Zhejiang University School of Medicine, Hangzhou, China. \\ * These authors contribute to this paper equally. \\ $\square$ Corresponding author: Professor Liping Cao, Department of General Surgery, Sir Run Run Shaw Hospital, the affiliated hospital of Zhejiang University \\ School of Medicine, No. 3, Qingchun Road, Hangzhou, 310000, China. E-mail: 11518310@zju.edu.cn \\ (c) Ivyspring International Publisher. This is an open access article distributed under the terms of the Creative Commons Attribution (CC BY-NC) license \\ (https://creativecommons.org/licenses/by-nc/4.0/). See http://ivyspring.com/terms for full terms and conditions.
}

Received: 2017.06.29; Accepted: 2017.12.08; Published: 2018.01.06

\begin{abstract}
Background: P38a is a ubiquitous protein kinase, which plays diverse roles in cancers. Surprisingly, P38 $\alpha$ functions vary markedly in different cancers (e.g., cancer suppressor vs cancer promoter). However, there is no report on the expression of $\mathrm{P} 38 \alpha$, the family's most important member, in pancreatic ductal adenocarcinoma (PDAC) and its association with clinicoathological parameters and patients' prognosis.

Materials and methods: We retrospectively analyzed 152 patients who underwent surgery and were pathologically diagnosed with PDAC from September 2013 to September 2015. We used immunohistochemistry to detect P38 $\alpha$ expression in tumor and adjacent normal tissues. The significance of the association between P38 $\alpha$ and clinicopathological parameters was evaluated using the $X^{2}$ test and $t$ tests. The Kaplan-Meier method was used to assess the association between $\mathrm{P} 38 \alpha$ expression and preoperative carbohydrate antigen 19-9 (CA19-9) levels and patients' overall survival. The Cox regression model was used to analyze the association between clinicopathological parameters, P38 $\alpha$ and preoperative CA19-9 levels, and prognosis. Statistical significance was defined as $P<0.05$.

Results: P38 $\alpha$ was expressed in $63.16 \%$ tumor tissues of PDAC, which was significantly higher compared with the adjacent normal tissues $(26.32 \%, P<0.001)$. High expression of $P 38 \alpha$ was associated with patients' histological grade $(P=0.013)$, lymphatic metastasis $(P=0.025)$ and TNM stage $(P=0.048)$. The median survival

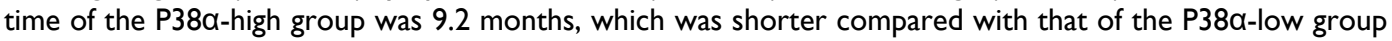
$(17.3$ months, $P=0.011)$. The median survival time of the CA19-9 $>43.63$ group was 11.1 months shorter than that of the CA19-9 $<43.63$ group $(24.8$ months, $P<0.001)$. The Cox regression model revealed that age $(P=$ $0.003)$, lymphatic invasion $(P=0.015)$, TNM stage $(P=0.003)$, histological grade $(P<0.001)$, preoperative CA19-9 $(P=0.049)$, and $P 38 \alpha$ expression $(P=0.008)$ were statistically significant independent risk factors affecting prognosis. Specifically, overall survival was 28.4 months in the P38a-low and CA19-9< 43.63 groups, 16.3 months in the P38a-high or CA19-9 > 43.63 groups, and 9.7 months in the P38a-high and CA19-9 > 43.63 groups $(P<0.001)$.

Conclusions: High expression of $\mathrm{P} 38 \alpha$ was significantly associated with histological grade, lymphatic metastasis, TNM stage and prognosis in patients with PDAC. P38 $\alpha$ and preoperative CA19-9 levels were independent risk factors affecting the prognosis of PDAC patients. High expression of $p 38 \alpha$ and preoperative carbohydrate antigen 19-9 indicate poor prognosis in patients with PDAC.
\end{abstract}

Key words: P38a, carbohydrate antigen 19-9, prognostic biomarker, pancreatic ductal adenocarcinoma.

\section{Introduction}

Owing to its special anatomical location and phenotypes, pancreatic ductal adenocarcinoma is highly malignant, and its dismal 5-year survival rate is only approximately $10 \%$ [1]. In 2015 , there were 
90,100 and 48,960 new cases of pancreatic ductal adenocarcinoma in China and the United States, respectively, and the ratios of new deaths to incidence for that year were $92 \%$ and $82.8 \%$, ranking pancreatic ductal adenocarcinoma as first and second among common malignancies, respectively $[2,3]$. Therefore, knowledge of the mechanism of the pathogenesis of pancreatic ductal adenocarcinoma has important clinical implications for improving patients' survival rate and quality of life.

P38a is a ubiquitous protein kinase that plays diverse roles in cancers. It is therefore surprising and puzzling that the role of P38a in different cancers markedly varies, even exerting opposing effects [4]. For example, P38 acts as a tumor suppressor in tumors such as gliomas, lung cancers, breast cancers, and liver cancers; however, in breast cancer, P38 promotes tumor metastasis and resistance to chemotherapy through mediating the epithelialmesenchymal transition and inhibition of apoptosis [4].

The P38 mitogen-activated protein kinase (MAPK) signaling pathway plays a key role in the response of cells to stress and participates in the regulation of numerous cellular processes. The known members of the P38 family are P38a (MAPK14), p38 $\beta$ (MAPK11), p38y (MAPK12), and p38ס (MAPK13). P38 a and p38 $\beta$ are widely expressed, although p38 $\mathrm{\gamma}$ and p38ס are expressed only in specific cell types [5]. At least 100 proteins can be directly phosphorylated by P38a, many of which are involved in the regulation of gene expression [6, 7]. Moreover, P38a can control the synthesis of extracellular signal transduction molecules at different levels, such as cytokines, chemokines, and growth factors [8].

The role of the P38 family in tumors has attracted increasing attention. For example, activation of P38 increases the invasiveness of pancreatic ductal adenocarcinoma [9, 10]. Most studies focus on the entire P38 family; however, there is no report on the expression of P38a (MAPK14), the family's most important member, in pancreatic ductal adenocarcinoma and its association with clinicoathological parameters and patients' prognosis. In the present study, our data suggests that P38a was significantly associated with the patients' histologic grade, lymphatic metastasis, TNM stage, preoperative CA19-9 levels and prognosis. The combination of P38a and CA19-9 improves the prognostic prediction in patients with pancreatic ductal adenocarcinoma.

\section{Materials and Methods}

\section{Patients and clinical parameters}

We retrospectively analyzed 152 patients who underwent surgery and were pathologically diagnosed with pancreatic ductal adenocarcinoma at Sir Run Run Shaw Hospital, the affiliated hospital of Zhejiang University School of Medicine, from September 2013 to September 2015. Clinical parameters were extracted from their medical record. Overall survival was defined as the time from pathological diagnosis to death or loss of follow-up. None of the patients received any types of treatments (radiation therapy, chemotherapy, or immunotherapy) before surgery.

\section{Western blot analysis}

Cell lines of pancreatic ductal adenocarcinoma were lysed with RIPA buffer (Sigma, USA) with a cocktail of protease inhibitors (Thermo, USA). Proteins were denatured in $2 \times$ SDS buffer at $95^{\circ} \mathrm{C}$, separated in $10 \%$ SDS-polyacrylamide gel electrophoresis (SDS-PAGE) and transferred onto polyvinylidene difluoride (PVDF) membrane (Millipore, Bedford, USA). After being blocked with $5 \%$ milk powder for $1 \mathrm{~h}$ at room temperature, the membrane was incubated with the following antibodies: rabbit anti-human polyclonal antibody against P38a (1:1000, Cell Signal Technology, USA), and mouse monoclonal anti-tubulin (1:2000, Abcam, $\mathrm{UK})$ as the control. The samples were incubated with the secondary goat anti-mouse antibody (1:5000, Pierce, USA) for $1 \mathrm{~h}$ at room temperature. The blots were visualized by GE Amersham Imager 600 .

\section{Immunohistochemistry and staining evaluation}

Rabbit anti-human polyclonal antibody against P38a (\#9218, Cell Signal Technology, USA), which detects endogenous levels of total p38a MAPK, regardless of its phosphorylation state, were used for staining. This antibody does not cross-react with other p38 MAPK isoforms such as $\beta, \gamma$ or $\delta .3 \mu \mathrm{m}$-thick tissue slides were deparaffinized in xylene and rehydrated in graded ethanol. Antigen retrieval was carried out with $0.01 \mathrm{M}$ citrate buffer $(\mathrm{pH}$ 6.0) and microwave heat induction for $15 \mathrm{~min}$. The slides were subsequently incubated for $10 \mathrm{~min}$ with hydrogen peroxide $(3 \%)$ to block endogenous peroxidase and then incubated overnight with the primary antibodies (dilution 1:100 for P38a) at $4^{\circ} \mathrm{C}$. After being washed in phosphate-buffered saline, the slides were incubated with the horseradish peroxidase-labelled secondary antibody for $30 \mathrm{~min}$. Diaminobenzidine was used as a chromogen for $5 \mathrm{~min}$.

Two pathologists independently evaluated and scored the slides without knowledge of clinical characteristics. When their evaluations were divergent, consensus was achieved through 
discussion.

\section{Statistical analysis}

The significance of the association between P38a and clinical parameters was evaluated using the $X^{2}$ test, $\mathrm{t}$ tests, one-sample Kolmogorov-Smirnov test and Mann-Whitney $U$ test. The discriminatory ability was assessed by building receiver operating characteristic curves (ROC) for P38a and preoperative CA19-9. The diagnostic value of the markers was evaluated based on area under the curve (AUC) and the evaluation of sensitivity and specificity at an optimal cutoff obtained by minimizing the total prediction error, by

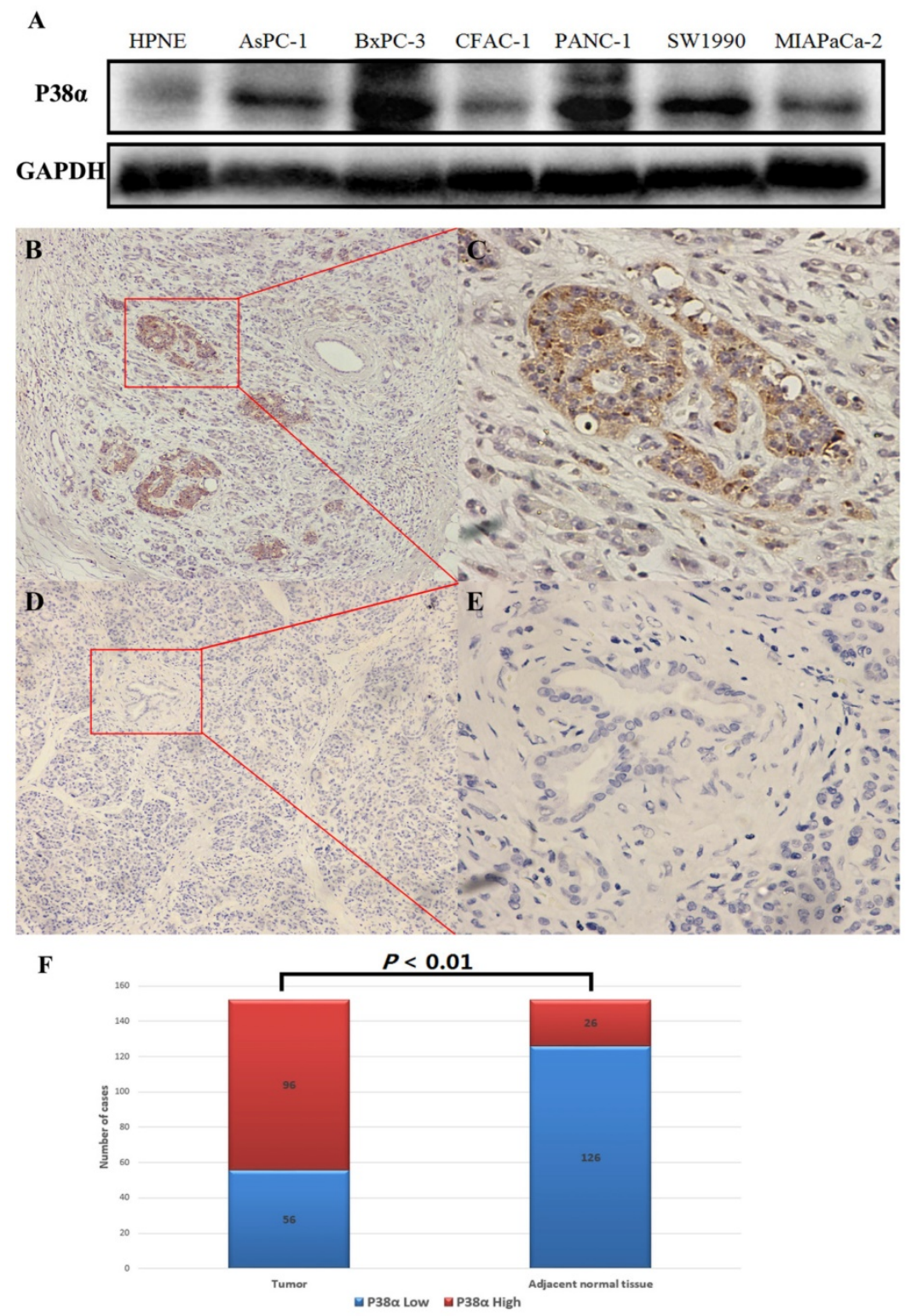

Figure 1. P38 expression in pancreatic ductal adenocarcinoma. (A) The pancreatic ductal adenocarcinoma cell lines expressed significantly higher levels of P38 $\alpha$ compared with the pancreatic duct epithelial cell line HPNE. (B-E) P38 $\alpha$ was mainly located in the cell membrane and cytoplasm. The $P 38 \alpha$ exression in tumor tissues $(B, \times 100, C, \times 400)$ was significantly higher compared with that of the corresponding adjacent normal tissues $(D, \times 100, E \times 400)(P<0.001)$. (F) The rate of detection of $\mathrm{P} 38 \alpha$ in tumor tissues $(63.16 \%, 96 / 152)$ was significantly higher compared with that of the corresponding normal tissues $(26.32 \%, 40 / 152)(P<0.001)$. the following formula: sensitivity - (1-specificity). The Kaplan-Meier analysis was used to assess the association between P38a expression and preoperative CA19-9 levels and patients' overall survival. The Cox regression model was used for multivariate analysis of prognostic factors. All the analyses were carried out using the statistical software SPSS V.19.0. A $P$ value $<0.05$ was considered to be statistically significant.

\section{Results}

\section{P38 $\alpha$ expression in pancreatic ductal adenocarcinoma}

The expression of P38a in six pancreatic cancer cell lines was detected using western blotting, and the pancreatic duct epithelial cell line HPNE served as the nontumorigenic control. The pancreatic cancer cell lines expressed significantly higher levels of P38a compared with HPNE cells (Fig 1A). The expression of P38a in 152 specimens each of tumor and adjacent normal tissues was detected using immunohistochemistry. P38a was mainly located in the cell membrane and cytoplasm. The rate of detection of P38a in tumor tissues $(63.16 \%, 96 / 152)$ was significantly higher compared with that of the corresponding adjacent normal tissues $(26.32 \%, 40 / 152)(\mathrm{P}<$ 0.01) (Fig 1B-1F).

\section{Association between P38 $\alpha$ and clinicopathological parameters}

We divided the 152 patients into a P38a-high group $(\mathrm{n}=96)$ and a P38a-low group $(n=56)$ according to the expression level of P38a. Higher expression of P38a in tumor tissues compared with that of adjacent normal tissues was significantly associated with tumor histologic grade $(P=0.013)$, lymphatic metastasis $(P=0.025)$, and TNM stage $(P=0.048)$. P38a expression in the poorly differentiation group (G3) was higher compared with that in the well-differentiated group (G1) $(P=$ 0.013) (Fig 2, Table 1). P38a expression in TNM I group was lower compared with that in TNM IV group $(P=0.048)$ (Fig 3, Table 1), but high P38a expression was not associated with other clinical parameters (Table 2). 


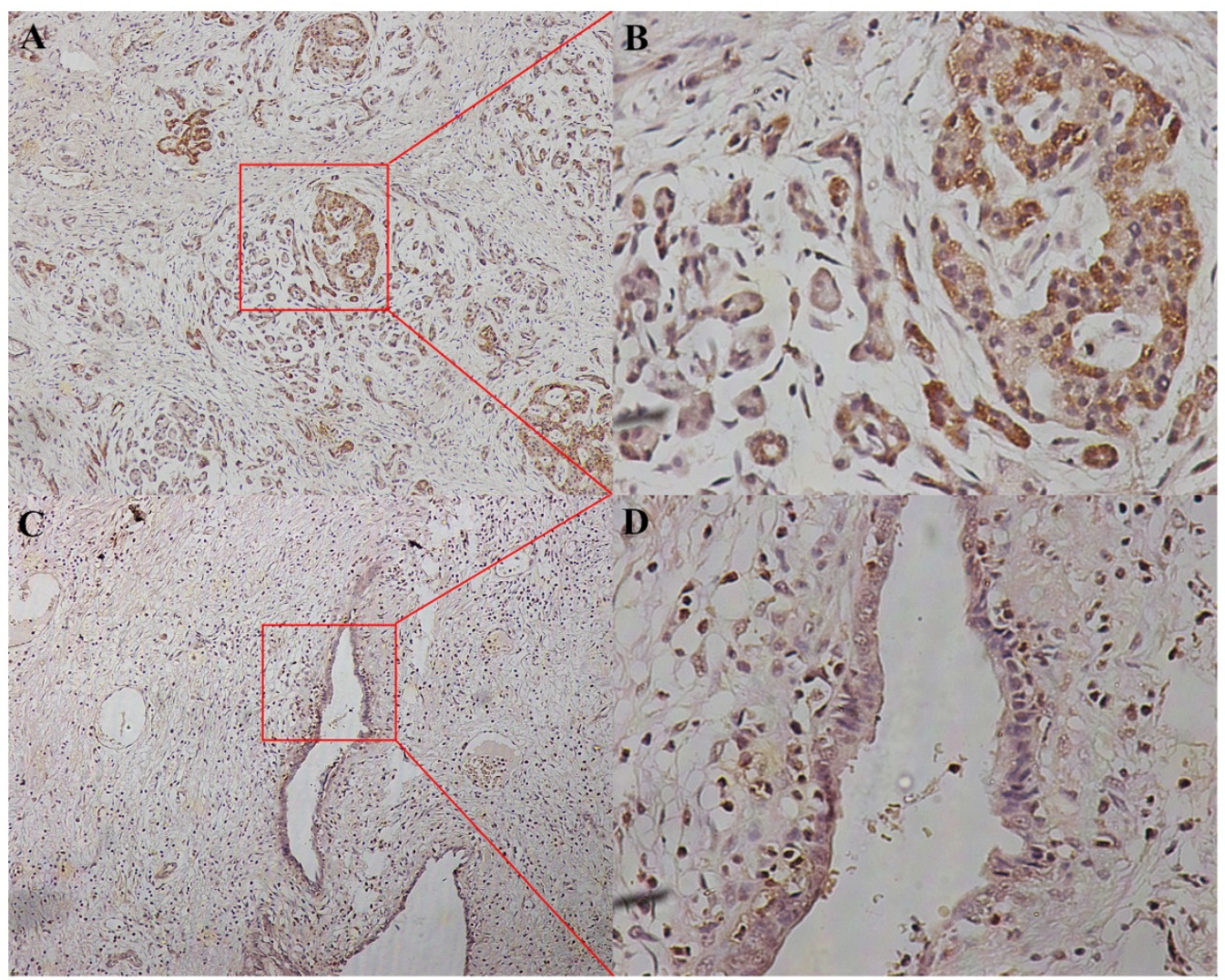

Figure 2. P38 $\alpha$ expression in different histologic grade. $P 38 \alpha$ expression in the poorly differentiation group $(G 3, A, \times 100, B, \times 400)$ was higher compared with that in the well-differentiated group $(G 1, C, \times 100, D, \times 400)(P=0.013)$.

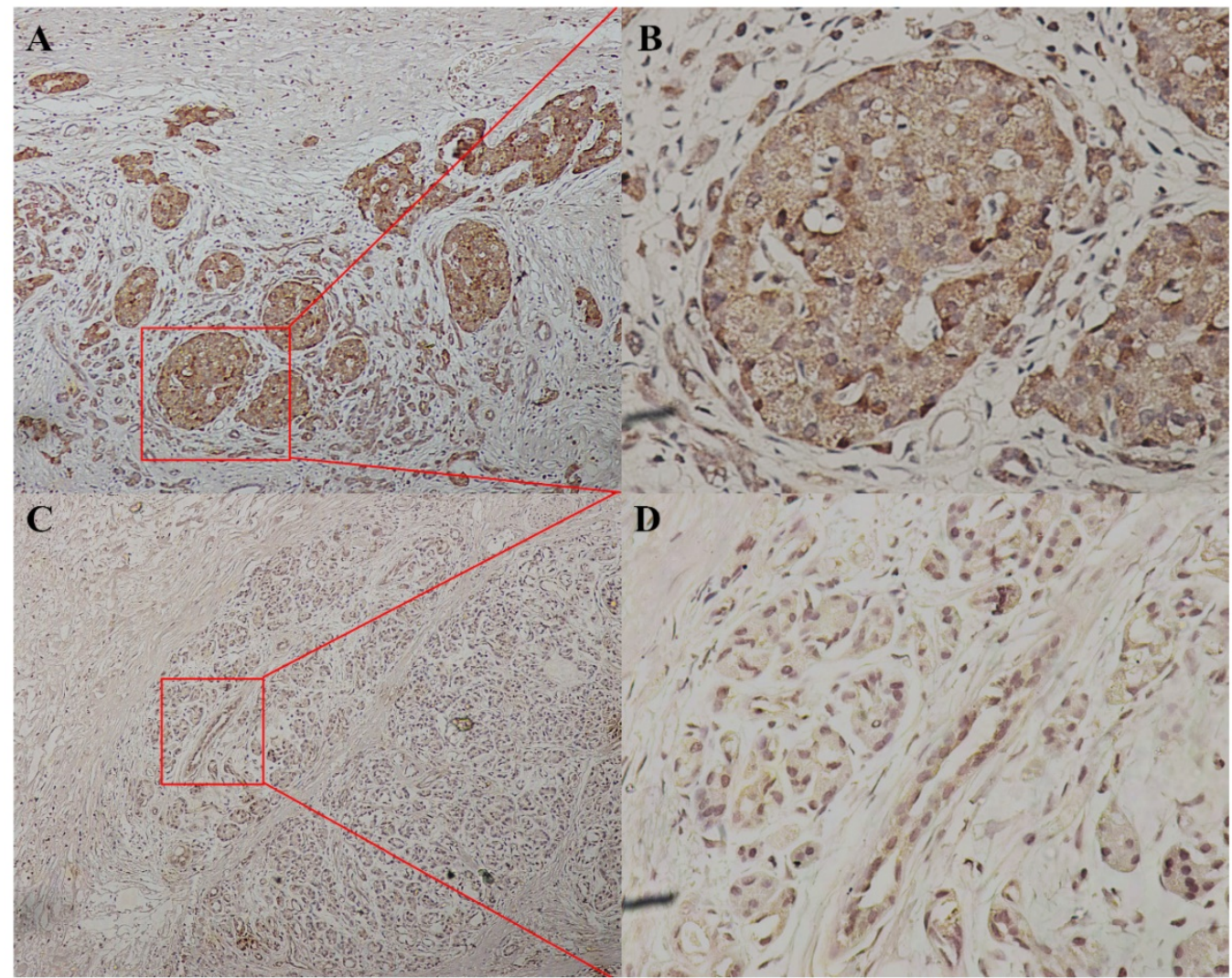

Figure 3. P38 $\alpha$ expression in different TNM stage. P38 $\alpha$ expression in TNM stage IV group $(A, \times 100, B, \times 400)$ was higher compared with that in TNM stage I group $(C, \times 100, D, \times 400)(P=0.048)$. 
Table 1. Association of P38 expression and clinicopathological parameters

\begin{tabular}{|c|c|c|c|c|}
\hline \multirow[t]{2}{*}{ Variable } & \multirow[t]{2}{*}{ (n) 152} & \multicolumn{2}{|c|}{ P38a expression } & \multirow[t]{2}{*}{$P$ value } \\
\hline & & low & high & \\
\hline \multicolumn{5}{|l|}{ Age } \\
\hline$<60$ & 71 & 29 & 42 & 0.338 \\
\hline$\geq 60$ & 81 & 27 & 54 & \\
\hline \multicolumn{5}{|l|}{ Gender } \\
\hline Male & 92 & 36 & 56 & 0.469 \\
\hline Female & 60 & 20 & 40 & \\
\hline \multicolumn{5}{|c|}{ Histological Grade } \\
\hline Grade 3 & 36 & 7 & 29 & $0.013^{*}$ \\
\hline Grade 1-2 & 116 & 49 & 67 & \\
\hline \multicolumn{5}{|l|}{ T Category } \\
\hline T1-2 & 56 & 20 & 36 & 0.826 \\
\hline T3-4 & 96 & 36 & 60 & \\
\hline \multicolumn{5}{|l|}{ N Category } \\
\hline No & 88 & 39 & 49 & $0.025^{*}$ \\
\hline N1-N2 & 64 & 17 & 47 & \\
\hline \multicolumn{5}{|c|}{ M Category } \\
\hline M0 & 138 & 50 & 88 & 0.624 \\
\hline M1 & 14 & 6 & 8 & \\
\hline \multicolumn{5}{|l|}{ TNM Stage } \\
\hline I-II & 120 & 49 & 71 & $0.048^{*}$ \\
\hline III-IV & 32 & 7 & 25 & \\
\hline
\end{tabular}

${ }^{*} P$ value $<0.05$, considered to be statistically significant.

Table 2. Association of $\mathrm{P} 38 \alpha$ expression and clinical parameters

\begin{tabular}{|c|c|c|c|c|c|}
\hline \multirow[t]{2}{*}{ Variable } & \multicolumn{2}{|l|}{ P38a expression } & \multirow{2}{*}{$\begin{array}{l}\text { normality } \\
\text { test }^{*}\end{array}$} & \multirow{2}{*}{$\begin{array}{l}\mathrm{t} \text { test } \\
P \\
\text { value }\end{array}$} & \multirow{2}{*}{$\begin{array}{l}\begin{array}{l}\mathrm{U} \\
\text { test }^{* *}\end{array} \\
P \\
\text { value }\end{array}$} \\
\hline & Low & High & & & \\
\hline ALT (U/L) & $76.21 \pm 82.05$ & $153.54 \pm 172.68$ & 0.020 & - & 0.238 \\
\hline AST (U/L) & $49.21 \pm 50.65$ & $91.96 \pm 95.59$ & 0.002 & - & 0.269 \\
\hline $\operatorname{ALP}(\mathrm{U} / \mathrm{L})$ & $322.79 \pm 409.96$ & $261.48 \pm 206.28$ & 0.052 & 0.549 & - \\
\hline GGT (U/L) & $366.07 \pm 523.86$ & $459.54 \pm 568.74$ & 0.007 & - & 0.296 \\
\hline albumin (g/L) & $39.78 \pm 4.57$ & $38.86 \pm 4.53$ & 0.999 & 0.551 & - \\
\hline $\begin{array}{l}\text { total bilirubin } \\
(\mu \mathrm{mol} / \mathrm{L})\end{array}$ & $88.4 \pm 107.47$ & $86.89 \pm 103.09$ & 0.902 & 0.966 & - \\
\hline LDH (U/L) & $172.86 \pm 49.79$ & $186.78 \pm 44.98$ & 0.501 & 0.386 & - \\
\hline $\begin{array}{l}\text { total bile acid } \\
(\mu \mathrm{mol} / \mathrm{L})\end{array}$ & $64.45 \pm 87.84$ & $83.21 \pm 121.78$ & 0.007 & - & 0.935 \\
\hline $\begin{array}{l}\text { C-reactive } \\
\text { protein }(\mathrm{mg} / \mathrm{L})\end{array}$ & $3.78 \pm 3.61$ & $8.92 \pm 14.24$ & 0.004 & - & 0.272 \\
\hline CA19-9 (U/ml) & $144.16 \pm 105.74$ & $319.18 \pm 345.27$ & 0.000 & - & 0.192 \\
\hline CA-125 (U/ml) & $\begin{array}{l}369.93 \pm \\
1332.65\end{array}$ & $26.035 \pm 24.98$ & 0.000 & - & 0.247 \\
\hline $\mathrm{AFP}(\mathrm{ng} / \mathrm{mL})$ & $2.41 \pm 1.37$ & $2.91 \pm 1.95$ & 0.300 & 0.407 & - \\
\hline CEA (ng/ml) & $26.17 \pm 85.62$ & $37.46 \pm 122.39$ & 0.000 & - & 0.188 \\
\hline
\end{tabular}

\section{Univariate and multivariate (Cox regression) survival analysis}

To investigate whether clinicopathological parameters are associated with clinical outcome of patients with pancreatic ductal adenocarcinoma, we calculated univariate and multivariable models (Table $3)$. The univariate analysis showed that overall survival was significantly correlated to gender $(P<$ $0.001)$, histological grade $(P<0.001)$, T category $(P<$ $0.001), \mathrm{N}$ category $(P<0.001)$, metastasis $(P=0.003)$,
TNM stage $(P<0.001)$, preoperative CA19-9 $(P<$ $0.001)$, CEA $(P<0.001)$, P38a $(P=0.011)$ and the combination of $\mathrm{P} 38 \mathrm{a}$ and preoperative CA19-9 $(P<$ $0.001)$. The multivariate analysis showed that overall survival was significantly correlated to age $(P=$ $0.003)$, N Category $(P=0.015)$, histologic grade $(P<$ $0.001)$, TNM stage $(P=0.003)$, preoperative CA19-9 $(P$ $=0.049), P 38 a(P=0.008)$ and the combination of P38a and preoperative CA19-9 $(P=0.008)$.

Table 3. Univariate and multivariate (Cox regression) survival analysis

\begin{tabular}{|c|c|c|c|c|}
\hline \multirow[t]{2}{*}{ Variable } & \multirow[t]{2}{*}{ Number } & \multirow{2}{*}{$\begin{array}{l}\text { Univariate } \\
\text { analysis } \\
P \text { value }\end{array}$} & \multicolumn{2}{|c|}{$\begin{array}{l}\text { Multivariable } \\
\text { analysis }\end{array}$} \\
\hline & & & $\begin{array}{l}\text { HR } \\
(95 \% \mathrm{CI})\end{array}$ & $P$ value \\
\hline Age (years) & & 0.085 & $1.016-1.080$ & $0.003^{*}$ \\
\hline$\geq 60$ & 81 & & & \\
\hline$<60$ & 71 & & & \\
\hline Gender & & $<0.001^{*}$ & $0.870-2.312$ & 0.161 \\
\hline Male & 92 & & & \\
\hline Female & 60 & & & \\
\hline Histological Grade & & $<0.001^{*}$ & $1.379-2.703$ & $<0.001^{*}$ \\
\hline Grade 3 & 36 & & & \\
\hline Grade 1-2 & 116 & & & \\
\hline T Category & & $<0.001^{*}$ & $0.628-1.388$ & 0.735 \\
\hline T3-4 & 96 & & & \\
\hline T1-2 & 56 & & & \\
\hline N Category & & $<0.001^{*}$ & $1.112-2.718$ & $0.015^{*}$ \\
\hline N1-N2 & 64 & & & \\
\hline No & 88 & & & \\
\hline M Category & & $0.003^{*}$ & $0.857-5.348$ & 0.103 \\
\hline M1 & 14 & & & \\
\hline M0 & 138 & & & \\
\hline TNM stage & & $<0.001^{*}$ & $1.127-1.773$ & $0.003^{*}$ \\
\hline III-IV & 32 & & & \\
\hline I-II & 120 & & & \\
\hline CA19-9 (U/ mL) & & $<0.001^{*}$ & $1.000-1.002$ & $0.049^{*}$ \\
\hline$\geq 43.63$ & 102 & & & \\
\hline$<43.63$ & 50 & & & \\
\hline CEA $(\mathrm{ng} / \mathrm{mL})$ & & $<0.001^{*}$ & $0.998-1.004$ & 0.446 \\
\hline$\geq 5$ & 52 & & & \\
\hline$<5$ & 100 & & & \\
\hline CA-125 (U/mL) & & 0.986 & $0.996-1.003$ & 0.629 \\
\hline$\geq 35$ & 28 & & & \\
\hline$<35$ & 124 & & & \\
\hline $\mathrm{P} 38 \mathrm{a}$ & & $0.011^{*}$ & $1.259-4.785$ & $0.008^{*}$ \\
\hline High & 90 & & & \\
\hline Low & 62 & & & \\
\hline P38a + CA19-9 & & $<0.001^{*}$ & & $0.008^{*}$ \\
\hline P38 $\alpha$ High and CA19-9 > 43.63 & 40 & $<0.001^{*}$ & $2.153-30.872$ & $0.002^{*}$ \\
\hline P38a High or CA19-9 > 43.63 & 69 & $<0.001^{*}$ & $1.370-10.642$ & $0.010^{*}$ \\
\hline P38a-low and CA19-9 $<43.63$ & 43 & $<0.001^{*}$ & Reference & Reference \\
\hline
\end{tabular}

${ }^{*} P$ value $<0.05$, considered to be statistically significant.

The median survival of the P38a-high group was 9.2 months (95\% CI $=7.6-10.8$ months) and that of the P38a-low group was 17.3 months $(95 \% \mathrm{CI}=13.9-20.6$ months). The overall survival (OS) of P38a-high group was significantly lower compared with that of the P38a-low group $(P=0.011)$ (Fig 4). Moreover, we analyzed P38a expression and its relationship with the OS of 174 patients in The Cancer Genome Atlas 
(TCGA) dataset using OncoLnc in www.oncolnc.org. The survival of the P38a-low group was significantly longer compared with that of the P38a-high group $(P$ $=0.0207$ ) (Fig 5).

We included CA19-9, the most important biomarker of PDAC, into the analysis of patients' prognosis. The discriminatory ability was assessed by building receiver operating characteristic (ROC) curves for P38a and preoperative CA19-9 (Fig 6). The optimal cutoff, which was obtained by minimizing the total prediction error as described in the methods, for preoperative CA19-9 level was $43.63 \mathrm{U} / \mathrm{mL}$ (AUC =
0.761 , sensitivity $81.5 \%$, specificity $68.2 \%$ ). We defined a cut-off value for preoperative CA19-9 level $=43.63$ $\mathrm{U} / \mathrm{mL}$, which divided patients into CA19-9-high and CA19-9-low groups, to evaluate the association of preoperative CA19-9 level with prognosis. The median survival time of the CA19-9-high and -low groups were 11.1 months and 24.8 months, respectively. Kaplan-Meier survival analysis of patients with high CA19-9 value (> $43.63 \mathrm{U} / \mathrm{mL})$ revealed a significantly poor overall survival compared to the patients with low CA19-9 value (< $43.63 \mathrm{U} / \mathrm{mL})(P<0.001$, Fig 7$)$.

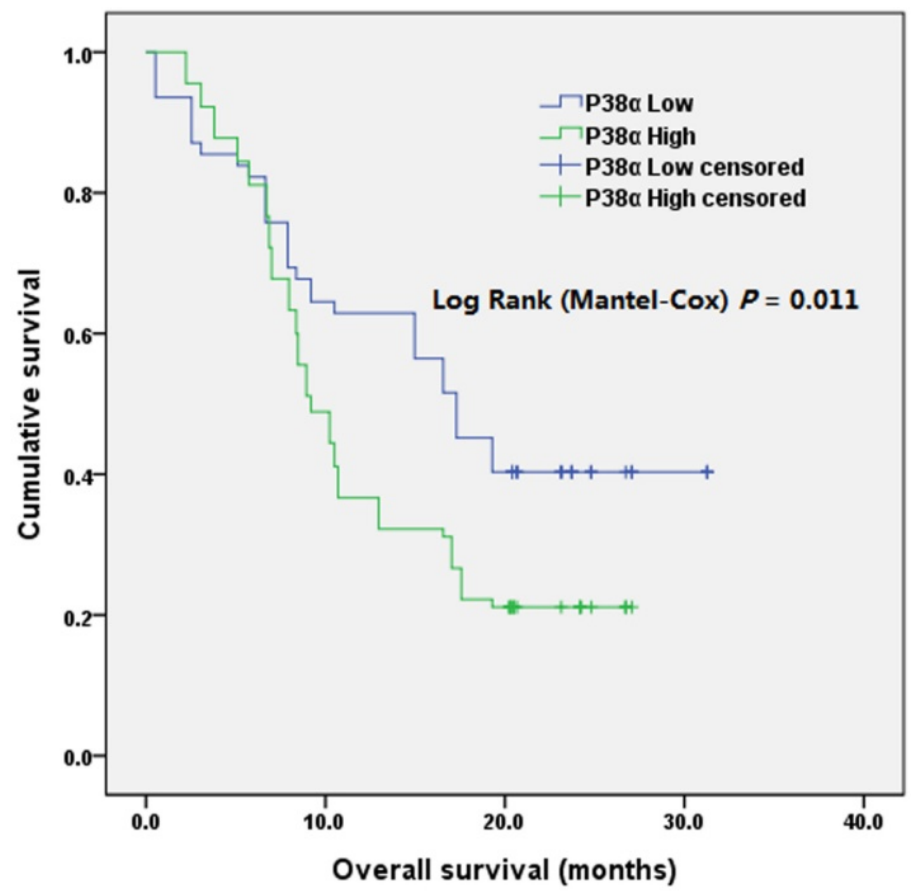

Figure 4. Overall survival according to P38a expression. The overall survival of patients in P38a-low group was significantly better than that of patients in P38a-high group $(P=0.011)$.

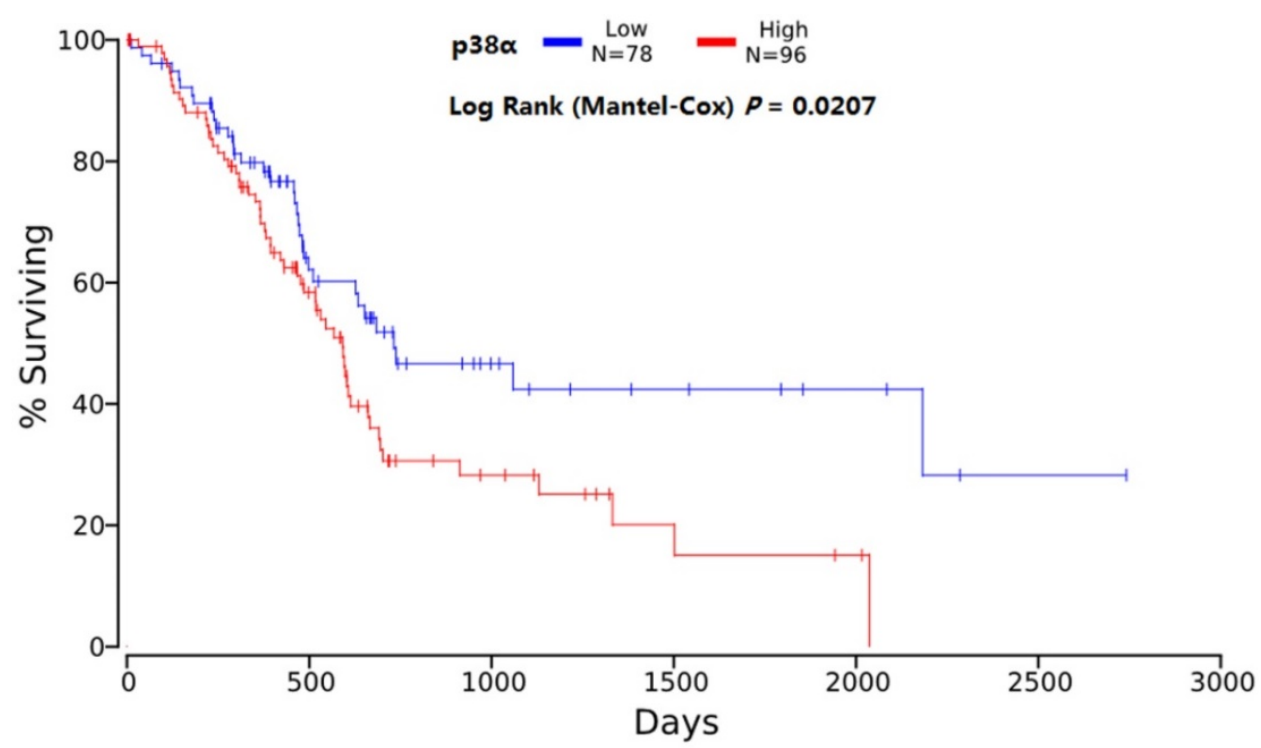

Figure 5. Overall survival analysis of TCGA. The survival of the P38a-low group was significantly longer compared with that of the P38 $\mathrm{a}$-high group $(P=$ 0.0207). 


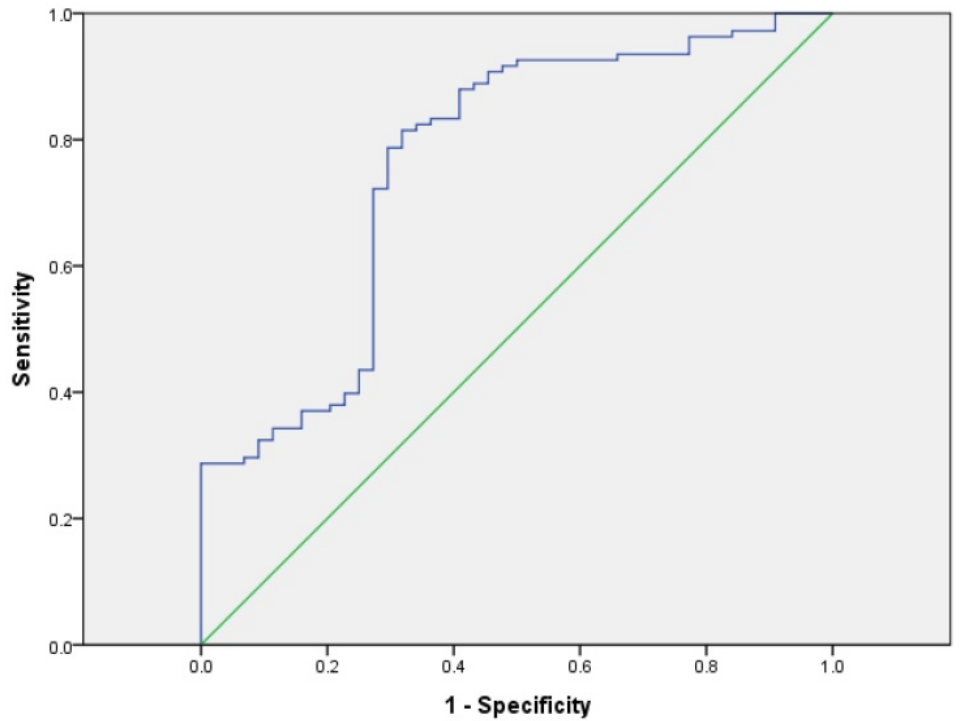

Figure 6. ROC curves for P38 $\alpha$ and preoperative CA19-9. The optimal cutoff for preoperative CA19-9 level was $43.63 \mathrm{U} / \mathrm{mL}$ (AUC $=0.761$, sensitivity $81.5 \%$, specificity $68.2 \%$ ).

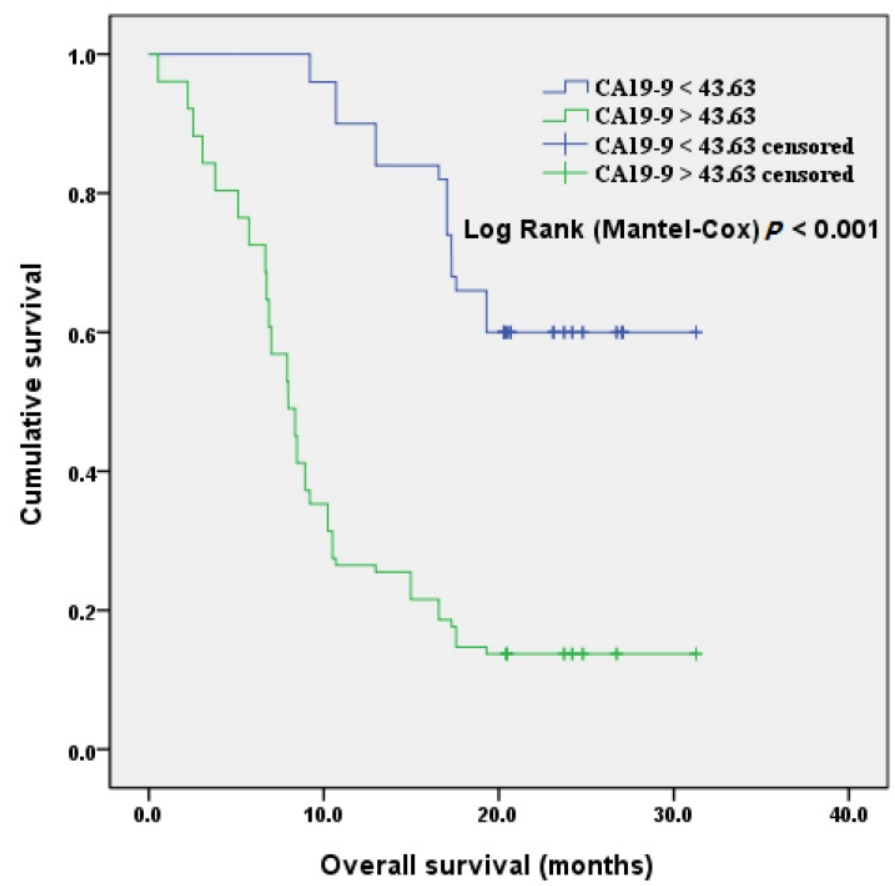

Figure 7. Overall survival according to preoperative CA19-9 values. The overall survival of patients with CA19-9 $<43.63 \mathrm{U} / \mathrm{ml}$ was significantly better than that of patients with CA19-9 $>43.63 \mathrm{U} / \mathrm{ml}(P<0.001)$

When we included P38a and preoperative CA19-9 values in the analysis of prognosis and divided the patients with pancreatic ductal adenocarcinoma into three groups. Kaplan-Meier analysis revealed that the overall survival of P38a-low and CA19-9 $<43.63$ group was 28.4 months $(95 \% \mathrm{CI}=$ 26.2 - 30.6 months, $P<0.001$ ), the overall survival of P38a High or CA19-9 $>43.63$ group was 16.3 months (95\% CI $=13.7-18.8$ months, $P<0.001)$, the overall survival of P38a High and CA19-9 $>43.63$ group was 9.7 months $(95 \% \mathrm{CI}=8.0-11.4$ months $)(P<0.001$, Fig 8).

\section{Discussion}

P38 plays a major role in the development and progression of tumors. However, it is very interesting that the role of P38 varies markedly in different tumors $[4,7,8,11]$. For example, P38 acts as a tumor suppressor in organs such as the brain, lung, breast, and liver, while it acts as a tumor promoter in other organs such as the large intestine and breast [4]. P38 can suppress gliomas by inhibiting glioma-initiating cell [12]. P38 interferes with malignant transformation of breast cancer cells through its effects on signaling 
pathways that mediate cell proliferation, differentiation, and the induction of apoptosis, and thus plays an important role in preventing the development of breast cancer [13]. P38 plays a protective role in lung cancer as well. For example, inhibiting P38 activity leads to excessive proliferation of lung epithelial cells and activation of K-RASG12V-mediated tumorigenesis, and the mechanism may be related to the ability of P38a to inhibit the proliferation and differentiation of lung stem cells [14]. In liver cancer, P38a can maintain the homeostasis of hepatocytes, and knockout of P38 can promote N-nitrosodiethylamineinduced hepatocellular carcinoma through enhanced production of reactive oxygen species and activation of the JNK/c-Jun pathway [15, 16].

However, P38 plays a role in promoting other tumors. For example, the P38 MAPK inhibitor SB202190 suppresses the growth of transplanted tumors and reduces the tumor burden in mice with colon cancer [17, 18]. The P38 MAPK inhibitor LY2228820 suppresses the growth of transplanted breast cancer in mice [19]. Moreover, P38 can promote the development and metastasis of tumors through multiple pathways, for example, by regulating epithelial interstitial transformation and angiogenesis and promoting inflammation [11].

Pancreatic ductal adenocarcinoma occurs in a special anatomical location and exhibits unique phenotypes, which contribute to its extremely high degree of malignancy and very poor prognosis. For example, activation of $\mathrm{P} 38$ promotes the proliferation, invasion, and metastasis of pancreatic cancer cells [20, 21]. In contrast, the suppression of $P 38$ activation prevents the progression of pancreatic cancer $[9,22]$. However, previous studies mainly focused on the P38 family. The expression levels of the P38 family members P38a (MAPK14), p38 $\beta$ (MAPK11), p38y (MAPK12), and p38ס (MAPK13) vary, and each isoform may play a unique role in different tumors [23]. This may explain why the roles of P38 are markedly in different tumors.

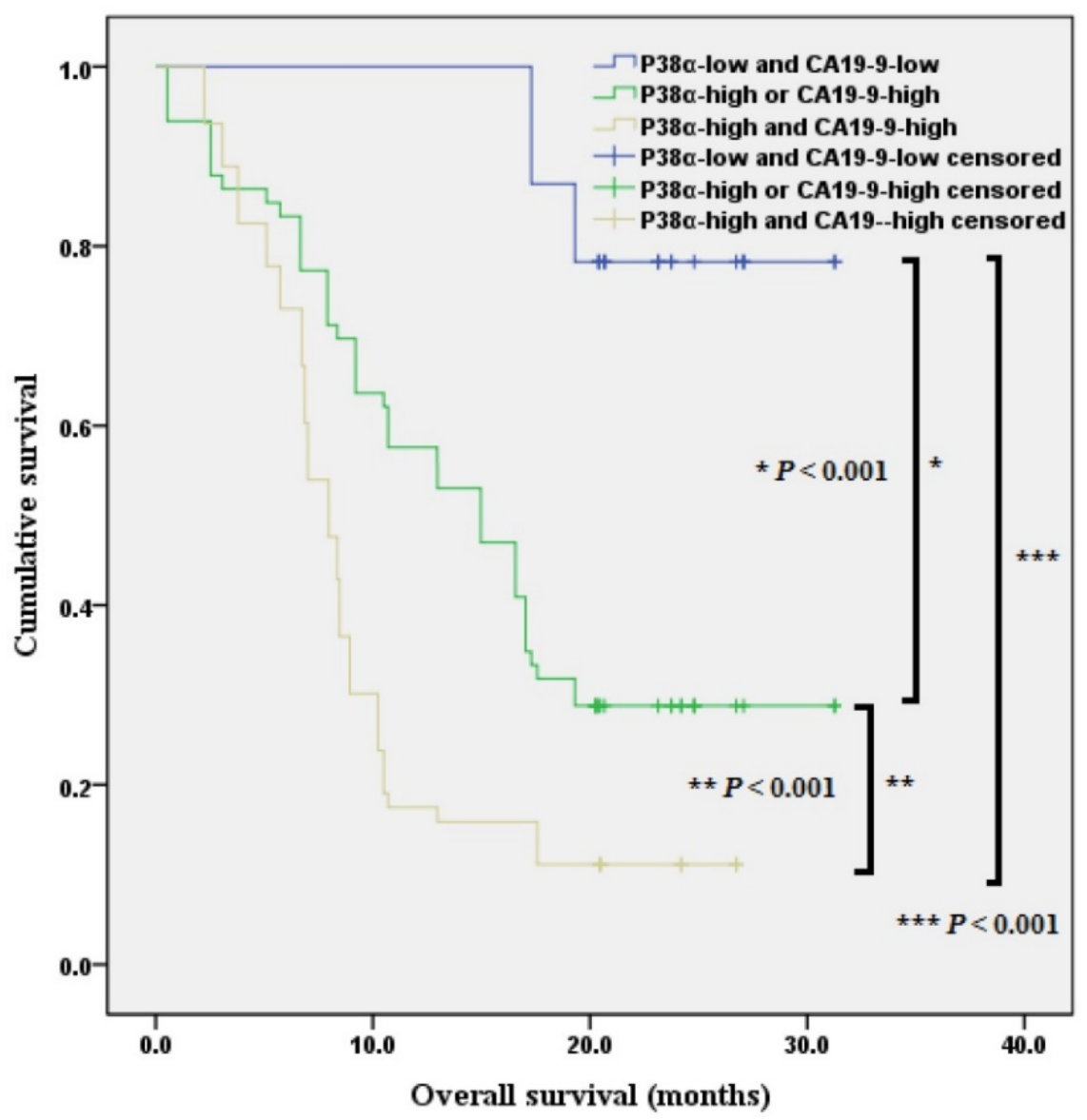

Figure 8. Combination of $P 38 \alpha$ and preoperative CA19-9 in overall survival analysis. The overall survival of $P 38 \alpha-l o w$ and CA19-9 $<43.63$ group, $P 38 \alpha$ High or CA19-9 > 43.63 group, P38 $\alpha$ High and CA19-9 > 43.63 group was 28.4 months, 16.3 months and 9.7 months separately $(P<0.001)$. 
In the present study, we performed immunohistochemical analysis to detect the expression of $\mathrm{P} 38 \mathrm{a}$, the most important member of the P38 family, in 152 surgical specimens of pancreatic ductal adenocarcinoma to assess its association with clinical data, pathological information, and prognosis. We found that relatively high expression of P38a in tumor tissues was associated with patients' histologic grade, lymphatic metastasis, TNM stage, and preoperative CA19-9 levels. The overall survival of P38a-high group was significantly lower compared with that of the P38a-low group. Moreover, the overall survival of patients with CA19-9 $<43.63 \mathrm{U} / \mathrm{ml}$ was significantly better than that of patients with CA19-9 > $43.63 \mathrm{U} / \mathrm{ml}$. Analysis of P38a expression, combined with the activity of preoperative CA19-9, showed that lymphatic metastasis, TNM stage, histological grade, preoperative CA19-9 levels and P38a expression were statistically significant independent risk factors affecting the prognosis. The CA19-9 has been reported as a predictive biomarker of prognosis in pancreatic ductal adenocarcinoma. Furthermore, several reports have suggested that the serial measurement of CA19-9 can predict the response to chemotherapy. However, the optimal cutoff values of CA19-9 have remained controversial [24-27]. Specifically, the expression of P38a combined with preoperative CA19-9 allowed for a better evaluation of prognosis in patients with pancreatic ductal adenocarcinoma.

In conclusion, P38a was significantly associated with the PDAC patients' histologic grade, lymphatic metastasis, TNM stage and prognosis. P38a expression and preoperative CA19-9 levels were independent risk factors affecting the prognosis of patients with pancreatic ductal adenocarcinoma. The combination of high expression of p38a and preoperative carbohydrate antigen 19-9 indicate poor prognosis in patients with pancreatic ductal adenocarcinoma. Further studies are required to verify the feasibility of using P38a as a potential target to treat pancreatic ductal adenocarcinoma.

\section{Acknowledgements}

This research was supported by Zhejiang Provincial Natural Science Foundation of China under Grant No.LY17H160015 and the National Natural Science Foundation of China (No. 81572323) and Zhejiang Provincial Medical and Health Science and Technology Program (No. 2018KY491).

\section{Ethics}

The study was approved by the Ethics Committee of Sir Run Run Shaw Hospital, Hanghzou, China.

\section{Competing Interests}

The authors have declared that no competing interest exists.

\section{References}

1. Sirri E, Castro FA, Kieschke J, Jansen L, Emrich K, Gondos A, et al. Recent Trends in Survival of Patients With Pancreatic Cancer in Germany and the United States. Pancreas. 2016; 45: 908-14.

2. Siegel RL, Miller KD, Jemal A. Cancer statistics, 2015. CA: a cancer journal for clinicians. 2015; 65: 5-29.

3. Chen W, Zheng R, Baade PD, Zhang S, Zeng H, Bray F, et al. Cancer statistics in China, 2015. CA: a cancer journal for clinicians. 2016; 66: 115-32.

4. Igea A, Nebreda AR. The Stress Kinase p38alpha as a Target for Cancer Therapy. Cancer Res. 2015; 75: 3997-4002.

5. Feng Y, Wen J, Chang CC. p38 Mitogen-activated protein kinase and hematologic malignancies. Archives of pathology \& laboratory medicine. 2009; 133: 1850-6.

6. Wagner EF, Nebreda AR. Signal integration by JNK and p38 MAPK pathways in cancer development. Nature reviews Cancer. 2009; 9: 537-49.

7. Cuenda A, Rousseau S. p38 MAP-kinases pathway regulation, function and role in human diseases. Biochimica et biophysica acta. 2007; 1773: 1358-75.

8. Cuadrado A, Nebreda AR. Mechanisms and functions of p38 MAPK signalling. The Biochemical journal. 2010; 429: 403-17.

9. Alam MS, Gaida MM, Bergmann F, Lasitschka F, Giese T, Giese NA, et al. Selective inhibition of the p38 alternative activation pathway in infiltrating T cells inhibits pancreatic cancer progression. Nat Med. 2015; 21: $1337-43$.

10. Dreissigacker U, Mueller MS, Unger M, Siegert P, Genze F, Gierschik P, et al. Oncogenic K-Ras down-regulates Rac1 and RhoA activity and enhances migration and invasion of pancreatic carcinoma cells through activation of p38. Cellular signalling. 2006; 18: 1156-68.

11. del Barco Barrantes I, Nebreda AR. Roles of p38 MAPKs in invasion and metastasis. Biochemical Society transactions. 2012; 40: 79-84.

12. Sato A, Okada M, Shibuya K, Watanabe E, Seino S, Narita Y, et al. Pivotal role for ROS activation of p38 MAPK in the control of differentiation and tumor-initiating capacity of glioma-initiating cells. Stem cell research. 2014; 12: 119-31.

13. Bulavin DV, Fornace AJ, Jr. p38 MAP kinase's emerging role as a tumor suppressor. Advances in cancer research. 2004; 92: 95-118.

14. Ventura JJ, Tenbaum S, Perdiguero E, Huth M, Guerra C, Barbacid M, et al. p38alpha MAP kinase is essential in lung stem and progenitor cell proliferation and differentiation. Nature genetics. 2007; 39: 750-8.

15. Sakurai T, He G, Matsuzawa A, Yu GY, Maeda S, Hardiman G, et al. Hepatocyte necrosis induced by oxidative stress and IL-1 alpha release mediate carcinogen-induced compensatory proliferation and liver tumorigenesis. Cancer Cell. 2008; 14: 156-65.

16. Hui L, Bakiri L, Mairhorfer A, Schweifer N, Haslinger C, Kenner L, et al. p38alpha suppresses normal and cancer cell proliferation by antagonizing the JNK-c-Jun pathway. Nature genetics. 2007; 39: 741-9.

17. Otsuka M, Kang YJ, Ren J, Jiang H, Wang Y, Omata M, et al. Distinct effects of p38alpha deletion in myeloid lineage and gut epithelia in mouse models of inflammatory bowel disease. Gastroenterology. 2010; 138: 1255-65, 65(e):1-9.

18. Gupta J, del Barco Barrantes I, Igea A, Sakellariou S, Pateras IS, Gorgoulis VG, et al. Dual function of p38alpha MAPK in colon cancer: suppression of colitis-associated tumor initiation but requirement for cancer cell survival. Cancer Cell. 2014; 25: 484-500.

19. Campbell RM, Anderson BD, Brooks NA, Brooks HB, Chan EM, De Dios A, et al. Characterization of LY2228820 dimesylate, a potent and selective inhibitor of p38 MAPK with antitumor activity. Molecular cancer therapeutics. 2014; 13: 364-74.

20. Taniuchi K, Furihata M, Hanazaki K, Iwasaki S, Tanaka K, Shimizu T, et al. Peroxiredoxin 1 promotes pancreatic cancer cell invasion by modulating p38 MAPK activity. Pancreas. 2015; 44: 331-40.

21. Cao L, Chen $X$, Xiao X, Ma Q, Li W. Resveratrol inhibits hyperglycemia-driven ROS-induced invasion and migration of pancreatic cancer cells via suppression of the ERK and p38 MAPK signaling pathways. International journal of oncology. 2016; 49: 735-43.

22. Cui XP, Qin CK, Zhang ZH, Su ZX, Liu X, Wang SK, et al. HOXA10 promotes cell invasion and MMP-3 expression via TGFbeta2-mediated activation of the p38 MAPK pathway in pancreatic cancer cells. Digestive diseases and sciences. 2014; 59: 1442-51. 
23. Koul HK, Pal M, Koul S. Role of p38 MAP Kinase Signal Transduction in Solid Tumors. Genes \& cancer. 2013; 4: 342-59.

24. Sugiura T, Uesaka K, Kanemoto H, Mizuno T, Sasaki K, Furukawa H, et al. Serum CA19-9 is a significant predictor among preoperative parameters for early recurrence after resection of pancreatic adenocarcinoma. Journal of gastrointestinal surgery: official journal of the Society for Surgery of the Alimentary Tract. 2012; 16: 977-85.

25. El Nakeeb A, El Shobary M, El Dosoky M, Nabeh A, El Sorogy M, El Eneen AA, et al. Prognostic factors affecting survival after pancreaticoduodenectomy for pancreatic adenocarcinoma (single center experience). Hepato-gastroenterology. 2014; 61: 1426-38.

26. Dong $Q$, Yang $X H$, Zhang $Y$, Jing $W$, Zheng LQ, Liu YP, et al. Elevated serum CA19-9 level is a promising predictor for poor prognosis in patients with resectable pancreatic ductal adenocarcinoma: a pilot study. World journal of surgical oncology. 2014; 12: 171.

27. Zhao JG, Hu Y, Liao Q, Niu ZY, Zhao YP. Prognostic significance of SUVmax and serum carbohydrate antigen 19-9 in pancreatic cancer. World journal of gastroenterology. 2014; 20: 5875-80. 